\title{
A PRODUÇ̃̃o DE IDENTIDADES SUL-MATO-GROSSENSES NAS PÁGINAS DAS CARTILHAS
}

\author{
THE PRODUCTION OF SOUTH-MATO-GROSSENSES IDENTITIES ON THE SPELLING BOOKS' PAGES
}

LA PRODUCCIÓN DE IDENTIDADES SUR-MATO-GROSSENSES EN LAS PÁGINAS DE LAS CARTILLAS

\author{
SILVA, Thaise 1 \\ BERTOLETTI, Estela Natalina Mantovani²
}

\section{RESUMO}

Neste estudo, analisa-se a influência dos livros didáticos (cartilhas e primeiros livros de leitura), na constituição da identidade do povo sul-mato-grossense, em especial dos moradores da Colônia Agrícola Nacional de Dourados, entre as décadas de 1950 e 1970. Para tanto, realizou-se uma pesquisa qualitativa de base documental, na qual foram examinados documentos da $6^{a}$ Delegacia de Ensino Primário de Dourados e materiais destinados ao ensino das primeiras letras. A partir dos documentos investigados, buscou-se compreender como a circulação de cartilhas e livros de leitura localizados apenas nesta região do estado influenciou na constituição da identidade do seu povo. Os resultados alcançados indicam que a circulação destes artefatos nessa região da Colônia se diferenciou das demais devido à influência do Governo Federal, além disso, os textos presentes nos materiais acabaram com contribuir para a constituição de uma identidade nacional aos moradores desta região. Palavras-chave: História da alfabetização. Livros didáticos de alfabetização. Identidade.

\section{ABSTRACT}

In this study, we analyze the influence of textbooks (spelling books and early reading books), in the constitution of the identity of the south-mato-grossense people, especially the residents of the National Agricultural Colony of Dourados, between the 1950s and 1970s. To do so, a qualitative research of documentary base was carried, in which documents were examined from the 6th Precint of Primary Education of Dourados and materials for the teaching of the first letters. From the documents investigated, it was sought to understand how the circulation of spelling books and reading books located only in this region of the state influenced in the constitution of the identity of its people. The results obtained indicate that the circulation of these artifacts in this region of the Colony differed from the others due to the influence of the Federal Government. In addition, the texts present in the materials ended up contributing to the constitution of a national identity to the residents of this region.

Keywords: History of literacy. Literacy textbooks. Identity.

\section{RESUMEN}

En este estudio, se analiza la influencia de los libros didácticos (cartillas y primeros libros de lectura), en la constitución de la identidad del pueblo sur-mato-grossense, en especial de los moradores de la Colonia Agrícola Nacional de Dourados, entre las décadas de 1950 y 1970. Para ello, se realizó una investigación cualitativa de base documental, en la cual se examinaron documentos de la $6^{a}$ Delegación de Enseñanza Primaria de Dourados y materiales destinados para la enseñanza de las primeras letras. A partir de los documentos investigados, se buscó comprender cómo la circulación de cartillas y libros de lectura ubicados solamente en esta región del estado influenció en la constitución de la identidad de su pueblo. Los resultados obtenidos indican que la circulación de estos artefactos en esta región de la Colonia se diferenció de los otros debido a la influencia del Gobierno Federal. Además, los textos presentes en los materiales acabaron contribuyendo para la constitución de una identidad nacional a los habitantes de esta región.

Palabras clave: Historia de la alfabetización. Libros didácticos de alfabetización. Identidad.

\footnotetext{
1 Universidade Federal de Grande Dourados - UFGD - Dourados - Mato Grosso do Sul - Brasil.

2 Universidade Estadual de Mato Grosso do Sul- UEMS - Dourados - Mato Grosso do Sul - Brasil.
} 


\section{INTRODUÇÃO}

Os livros escolares destinados à alfabetização e ao ensino da leitura são artefatos importantes para o desenvolvimento de estudos e pesquisas, uma vez que trazem consigo a história e os discursos que marcaram cada fase por que passou o ensino em nosso país.

Darnton (1990), em seus estudos sobre o circuito da comunicação do livro, alerta que, embora negligenciado até 1960 , tal tema passou a ser desde então um objeto de estudo que se amplia constantemente na contemporaneidade. Segundo esse autor, além dos aspectos econômicos, históricos, políticos, culturais e sociais que envolvem a produção desse material, um dos motivos da intensidade de estudos referentes ao tema é a abrangência desse objeto.

Diante desta perspectiva, e compreendendo o livro didático como objeto da cultura escrita constituído por um conjunto de saberes legitimados em uma determinada época - saberes culturais, sociais e pedagógicos -, este artigo tem por objetivo analisar a influência dos livros didáticos destinados à alfabetização e às primeiras letras de escolas públicas na constituição da identidade de uma parcela do povo sul-mato-grossense. O recorte espaço-temporal se restringe à região que compreende a Colônia Agrícola Nacional de Dourados (CAND), localizada no extremo sul do estado de Mato Grosso², entre o final dos anos 1950 e início dos anos 1970, período em que a Colônia viveu seu apogeu e declínio. A partir do levantamento e da análise de algumas destas cartilhas e livros, é possível perceber quais os discursos que circulavam na região e como esses acabaram por subjetivar os estudantes do recém-criado município de Dourados ${ }^{4}$, contribuindo para a formação de suas identidades.

O recorte temporal deve-se ao fato de ser este período marcado por grande ocupação de terras e expansão demográfica no sul do estado de Mato Grosso, com a chegada de levas de migrantes de várias regiões do Brasil e de imigrantes, que levou à ampliação do número de escolas e de pessoas com acesso a ela.

A investigação aqui realizada teve por base metodológica a análise textual que associada à análise do discurso, serviu como suporte para a análise dos livros de leitura e das cartilhas que circularam na região no período investigado. Barker e Galasinski $(2001$, p.1) afirmam que a "Análise Crítica do Discurso é capaz de oferecer o entendimento, habilidades e ferramentas com as quais se pode demonstrar o lugar da linguagem na construção, constituição e regulação do mundo social". Segundo Gill (2004, p. 244), essa perspectiva não considera a linguagem como algo neutro que apenas descreve o mundo e reflete sobre ele, mas acredita que o discurso constrói a vida social.

\footnotetext{
${ }^{3}$ Referimo-nos ao espaço que corresponde, hoje, à região denominada Grande Dourados, localizada no sudoeste do estado de Mato Grosso do Sul. No período abordado por este estudo, entretanto, este ainda não era um estado constituído, e seu território pertencia ao estado do Mato Grosso. A divisão do estado ocorreu somente em 1977, pela Lei Complementar $n^{\circ} 31$. Mesmo assim preferimos, ao longo do texto, nos referir ao Mato Grosso do Sul pela especificidade regional que abordamos.

${ }^{4} \mathrm{Em} 20$ de dezembro de 1935, com áreas desmembradas do município de Ponta Porã, através do Decreto $\mathrm{n}^{\circ} 30$ do então Governador do Estado, Sr. Mário Corrêa da Costa, foi criado o município de Dourados, um dos municípios que compõe a, hoje, considerada região da Grande Dourados.
} 
Barker e Galasinski (2001, p. 07) explicam que a análise textual trabalha com a concepção de que os textos são polissêmicos. "O entendimento cultural dos textos não pode permanecer com o texto, mas deve se relacionar por si só com os processos envolvidos na compreensão do significado pelos leitores". Frente a isso, os Estudos Culturais procuram verificar como ocorre o "consumo" e a recepção desses materiais, pensando que o indivíduo não apenas é um receptor passivo, mas também criador ativo de significados.

Diante do exposto, neste estudo opta-se por utilizar como aporte teórico uma concepção pósestruturalista, a partir do campo dos Estudos Culturais. Com isso, não se almeja produzir verdades e certezas, mas lançar novos olhares sobre o que vem sendo visto nessa área. A seção que segue aproximará o leitor do campo teórico que serviu de base para a investigação.

\section{CONTEXTUALIZANDO O CAMPO}

Segundo Costa (2000), a modernidade e sua forma de produzir pesquisa caracterizavam-se como sendo um método que, se bem aplicado, produziria "a" verdade sobre o que seria avaliado. Esse rigor científico asseguraria a neutralidade, a objetividade e a assepsia conceitual do objeto analisado. Em contrapartida, a pós-modernidade caracteriza a pesquisa e os conhecimentos produzidos por ela como sendo uma prática social inserida em um processo histórico coletivamente construído. Os Estudos Culturais aproximam-se do pós-estruturalismo nas questões referentes à linguagem e no poder constituidor dos discursos (BARKER; GALASINSKI, 2001).

Dentro desse campo de estudos entende-se por cultura os modos de vida de uma população. Essa concepção vem ao encontro da abordagem dada à cultura pelos Estudos Culturais que a definem como o modo de vida global de uma sociedade (COSTA; SILVEIRA; SOMMER, 2003). Assim, a cultura deixa de ser unitária e soberana e passa a ser plural, fruto de disputas entre as diferentes identidades que compõem o cenário atual, sendo impossível trabalhar com esse conceito sem relacioná-lo com as estratégias de mudança social e as relações de poder. (MATTELART, 2004, p. 50).

O papel central dado à cultura passa a ter uma dimensão epistemológica denominada de "virada cultural5", referindo-se ao poder instituidor dos discursos que circulam nesse espaço cultural. Esse poder se manifesta por meio dos artefatos produtivos (notícias veiculadas pelos meios de comunicação, livros didáticos, músicas, filmes, entre outros) que, pelas práticas de representação, produzem sentidos que circulam e operam nos meios culturais, nos quais os significados são estabelecidos (VEIGA-NETO, 2003).

Para que se possa entender o conceito de cultura como um campo de disputas, faz-se necessário entender o conceito de poder dentro desse contexto. De acordo com Veiga-Neto (1995), dando ênfase a uma visão foucaultiana de poder, esse não é visto como sendo algo que possui apenas

\footnotetext{
5 Stuart Hall, Fredric Jameson, Néstor Canclini, Beatriz Sarlo e David Harvey são alguns pensadores que trabalham com a temática da centralidade da cultura.
} 
um lado eficiente, poderoso, dominante e central, mas sim como atuante e funcionando de inúmeras formas, capilarizando-se no tecido social, como uma rede de fluxo constante de forças e resistência. Nesse sentido, o poder torna-se produtivo, já que gera saberes, produz discursos, produz sujeitos, atravessando todo o corpo social.

A linguagem, sob essa ótica, tem um papel central, pelo fato de ser ela a responsável pela produção de significados - sendo esses constantemente ressignificados por meio das lutas que ocorrem entre o simbólico e o discursivo, uma vez que são as práticas discursivas que constituem e subjetivam sujeitos e objetos, e não apenas transmitem significados. A linguagem não é um meio neutro de explicar e representar o mundo, mas é a constituidora do discurso, tornando-se crucial na construção da vida social.

A essa forma de perceber a linguagem denomina-se "virada linguística". Nesse contexto, a ideia de sujeito uno se desfaz e surge a ideia de um sujeito constituído por múltiplas identidades que se compõem por meio das/nas narrativas formuladas nas confluências discursivas (ARFUCH, 2002). Logo, ao se produzir um enunciado, não é o nosso pensamento em essência que está sendo expresso, mas a pluralidade de vozes que nos constituem no decorrer de nossas vivências sociais e históricas.

As narrativas assim passam a ser vistas como constituidoras do sujeito e, de acordo com Larrosa (1996), elas produzem as identidades, partindo-se da ideia de que somos o que contamos e o que nos contam, sob a influência de lugares, tempo e vozes que narram, fazendo com que a narrativa se torne responsável pela formulação dos processos identitários. Com a "virada linguística", a verdade única deixa de existir, sendo substituída por verdades constituídas. Essas, a partir de então, são consideradas crenças, tendo como alvo de análise o processo pelo qual algo se torna verdade (SILVA, 1999).

Os discursos, dentro dessa perspectiva, são entendidos como práticas que instituem significados por meio dos quais se torna possível nomear, classificar, julgar, incluir e excluir ideias, pessoas, coisas e objetos, buscando pôr em evidência o funcionamento de mecanismos instituidores de significados. Foucault (1996) explica que a linguagem, e consequentemente os discursos, não funcionam imunes aos controles sociais porque são atravessados pelas relações de poder. Barker e Galasinski (2001, p. 12-13) passam a definir o sujeito, dentro desse contexto, como deixando de ser entendido como estável e universal e se tornando um efeito do discurso que o constitui. A subjetividade passa a ser considerada uma produção discursiva, e o sujeito falante é dependente da existência prévia de posições discursivas por meio das quais se compreende o mundo.

\section{ROTAS MIGRATÓRIAS E A CIRCULAÇÃO DOS LIVROS DESTINADOS AO ENSINO DAS PRIMEIRAS LETRAS NA CAND}

Como já foi anunciado, nesta investigação analisamos uma região específica do estado do Mato Grosso do Sul conhecida hoje por Grande Dourados. A opção por este recorte espacial se deve 
às especificidades regionais que marcam esse estado. A extensão territorial, os limites geográficos, as políticas de governo e a distância da capital, que à época em que ocorreu a investigação era Cuiabá e ficava a quase 1000 quilômetros de distância dessa região, fez com que a cultura e identidade do povo desse estado se tornassem múltiplas.

Esta região fica localizada no sudoeste do estado de Mato Grosso do Sul - extremo sul do antigo Mato Grosso - fazendo parte do projeto de colonização do Estado Novo do Governo de Getúlio Vargas (1930-1945), conhecido por "Marcha para o Oeste", que culminou com a implantação da Colônia Agrícola Nacional de Dourados (CAND) ${ }^{6}$. Esse projeto estava subordinado a um plano econômico desenvolvimentista, que pretendia fazer do país uma potência econômico-industrial, porém o que torna essa região diferente das demais do estado era a preocupação que havia na época com a ocupação das terras e consolidação da identidade e do território brasileiro, uma vez que, segundo Moreira (2014), existia uma preocupação com a política de colonização, pois em Mato Grosso do Sul havia uma concentração de propriedades em nome de grupos estrangeiros.

Um dos objetivos da criação da CAND era a ocupação das terras por colonos, em sua maioria, atraídos pelas campanhas de distribuição gratuita de lotes pelo governo.

As peculiaridades da região, portanto, caracterizavam moradores com crenças, valores e formas de pensar bem distintas, constitutivas de identidades também distintas e múltiplas. Isso preocupava o Governo Federal que tomou uma série de medidas para fazer com que os colonos e demais moradores desenvolvessem o sentimento de pertencimento pátrio, religiosidade e cidadania. Dentre elas, a escola e os livros didáticos adotados para o trabalho escolar serviram como artefatos para a produção de novas identidades.

No que diz respeito à educação escolar, a criação da Colônia proporcionou o surgimento das primeiras escolas urbanas, de escolas agrícolas e a expansão de escolas rurais, uma vez que o Governo Federal custeava financeiramente classes de ensino primário7. Outra peculiaridade é que somente com a criação da CAND a ação pública passou a ofertar o ensino primário, uma vez que o Decreto Municipal $n^{\circ} 70$, de 1946 , obrigava todos os filhos de colonos residentes na Colônia a ter acesso à instrução primária gratuita, sendo obrigatória a frequência, que caso não ocorresse gerava uma multa de $\operatorname{Cr} \$ 100,00$ para os pais, além do comparecimento obrigatório à autoridade policial. (GRESSLER; SWENSSON, 1988).

Como é possível perceber, a estratégia utilizada pelo Governo Federal para constituir uma identidade a uma população oriunda de muitos países e regiões, além dos da população nativa

\footnotetext{
6 Segundo Ponciano (2006) a CAND foi criada em 1943, pelo Decreto-lei n 5.941 , de 28 de outubro, e teve sua real implantação em 20 de julho de 1948, pelo então Presidente da República, Eurico Gaspar Dutra (1946-1951), quando ocorreu a demarcação de suas terras pelo Governo Federal, por meio do Decreto-lei $n^{\circ} 87$, que reservava uma área de aproximadamente 300.000 hectares onde hoje estão localizados os municípios de Dourados, Fátima do Sul, Vicentina, Jateí, Douradina, Glória de Dourados e Deodápolis.

${ }^{7}$ Até então a educação na região acontecia, principalmente, nas fazendas da região, ou nas próprias casas dos professores ou dos alunos (IRALA et al, 2014).
} 
formada por índios e "brasiguaios 8 " era por meio da educação escolarizada. Luke (2000, p. 93) nos leva a analisar o "[...] modo como as relações sociais, a identidade, o conhecimento e o poder são construídos por meio de textos falados e escritos nas comunidades, nas escolas e nas salas de aula", uma vez que a linguagem e o discurso não são neutros ou transparentes, não apenas descrevem ou analisam o mundo, mas os constroem e regulam por meio de conhecimentos legitimados. Os livros didáticos que circularam na CAND funcionaram como dispositivos para que tal fim fosse consolidado.

Silva (2017), ao analisar as rotas de circulação das cartilhas e dos livros de leitura no período investigado e comparando com estudos desenvolvidos por Amâncio e Cardoso (2006) e Bertoletti e Silva (2016) sobre o mesmo tema, identifica que alguns livros que circularam nas escolas públicas do então estado do Mato Grosso foram encontrados na CAND, o que é esperado uma vez que se tratava de uma mesma unidade da federação e existia toda uma política de governo em nível estadual que tentava unificar as metodologias e os materiais a serem adotados e utilizados nas escolas (SILVA; BERTOLETTI, 2017), no entanto ao aprofundar seus estudos Silva e Bertoletti (n.d.) identificaram alguns títulos que circularam apenas nessa região. As autoras descobriram que isso ocorreu devido à influência do Governo Federal que fez com que estes materiais chegassem especificamente a essa região do estado, uma vez que era sobre ela que o "poder federal" tinha influência maior devido à política de governo instaurada na região.

Diante disso, passamos na seção seguinte a analisar uma das coleções citadas pelas autoras no intuito de identificar quais os discursos presentes nestes materiais e o quanto eles passaram a subjetivar os estudantes da região influenciando na constituição das identidades do povo desta parte do estado.

\section{CARTILHAS E LIVROS DE LEITURA: A CONSTITUIÇÃO DA IDENTIDADE DE UM POVO}

Para esta análise escolhemos a série de leitura Vamos Sorrir. A opção por este material se deve a dois fatores: 1. termos localizado, no Centro de Documentação Regional da Universidade Federal da Grande Dourados (CDR/UFGD), no acervo denominado Diretoria Regional de Ensino de Dourados (DRE), documentos que mencionam a sua utilização; e, 2. termos tido acesso a todos os livros e ao Manual do Professor da cartilha que compõem a série.

Os livros de leitura da coleção Vamos Sorrir foram escritos ${ }^{9}$ por Maria Braz e Candido Oliveira. Faz parte de uma coleção que inicia com a cartilha, acompanhada de outros cinco livros destinados à leitura do primeiro ao quinto ano, todos com o mesmo título, Vamos Sorrir. Esses vêm acompanhados pelo subtítulo que identifica em algarismos romanos $\mathrm{o}$ ano ao qual se destinam. A capa e as ilustrações de todos os livros da coleção foram produzidas pelo Stúdio Ito.

\footnotetext{
${ }^{8}$ Chamamos de "brasiguaios" os brasileiros e os paraguaios que vivem em áreas fronteiriças entre Paraguai e Brasil, ora habitando um lado ora outro da fronteira.

${ }^{9}$ A cartilha e o quinto livro são de autoria apenas de Maria Braz.
} 
Vamos Sorrir foi publicada pela FTD, editora fundada no Brasil em 1902 que desde a sua origem se dedicou à publicação de livros escolares. A coleção foi organizada de acordo com padrão denominado pela FTD de Método FTD, que incluía a publicação da série de leitura para todos os níveis de ensino, sempre acompanhada do Livro do Mestre. Segundo Hallewell (2012), esta produção no formato de Coleções Didáticas revela o viés comercial, uma vez que ao se optar por um livro, toda a coleção acaba sendo adquirida.

A coleção Vamos Sorrir foi escrita para uso de professores, ao contrário de alguns materiais que circularam na região da Colônia, que podiam ser utilizados por qualquer pessoa alfabetizada que estivesse disposta a ensinar a ler e escrever. O manual que acompanha a cartilha e os demais livros da coleção é intitulado Livro do Professor. A cartilha e os livros de leitura são destinados apenas ao público infantil, embora outros livros didáticos que circularam na CAND se destinassem a pessoas não alfabetizadas, independentemente da idade, uma vez que o número de analfabetos ${ }^{10}$ na região era alto. Isso foi possível perceber mediante os textos, as imagens presentes nos livros analisados e as orientações contidas no Livro do Professor.

As capas de todos os volumes trazem projetos gráficos diferentes, porém com temáticas semelhantes. Em todos os exemplares o nome da/os autora/es aparecem no canto superior esquerdo da capa, no outro extremo aparece o nome da coleção Vamos Sorrir, em destaque, seguido pelo ano a que se destina. Ao analisar os textos verbais presentes nas capas percebemos que o título faz inferência à alegria; associa-se o conhecimento e o estudo à satisfação. Evangelista e Rocha (1998) afirmam que esse é um recurso utilizado para chamar a atenção do leitor e convidá-lo a entrar na obra. Aliar o prazer à aprendizagem fazia parte do movimento da Escola Nova, que embora tenha chegado ao Brasil em 1882, pelas mãos de Rui Barbosa, começa a ganhar força nas décadas de 1920 e 1930.

Observando as capas, é possível mostrar algumas regularidades discursivas representadas por textos não verbais. Na cartilha e nos livros de leitura do II e III anos aparecem desenhos de duas crianças brancas, asseadas, uniformizadas indo para a escola, sorridentes. Aparentemente trata-se do mesmo menino e menina só que com idades diferentes em um e outro exemplar, dando a impressão de que as crianças foram crescendo ao longo dos anos. Ao analisar as capas e os textos da cartilha e dos livros de leitura percebemos neles o ideário da Escola Nova marcado por temas infantis e a alegria em ser criança. Silva e Bertoletti (2017), ao analisarem a legislação estadual apontam que desde a criação do Decreto $n^{\circ} 759$, de 22 de abril de 1927, que regulamentava a Instrução Pública Primária do Estado de Mato Grosso, havia uma preocupação em tornar a aprendizagem algo concreto e mais prazeroso. Com a promulgação da Lei no 452, de 24 de novembro de 1951, Lei Orgânica do Ensino Primário do estado de Mato Grosso, inspirada no Decreto-lei $n^{\circ} 8.529$, de 2 de janeiro de 1946 - Lei Orgânica do Ensino Primário -, que substituiu o Regulamento de 1927, amplia-se a influência do discurso da Escola Nova deixando mais evidente a importância do aprender com significado e prazer.

\footnotetext{
10 Segundo as Diretrizes para a Educação do Mato-Grosso, em 1940, a população analfabeta do estado chegava a 99,5\%, sendo reduzida para 55,6\% em 1950 (MATO GROSSO, 1965).
} 
A capa do I livro de leitura traz a imagem de uma menina, um menino e uma pessoa de mais idade, que pode ser a mãe ou a avó, todos loiros, sentados no sofá de casa com livros nas mãos. As crianças parecem ouvir atentamente $\mathrm{o}$ adulto lendo as histórias do livro. Aqui o convite ao encantamento se dá por meio da prática de ler e ouvir histórias, algo que deveria proporcionar prazer. Peres (2003) chama a atenção para o fato de que, desde a década de 1930, havia uma preocupação em promover um trabalho dentro da área da linguagem, cujo objetivo era o de prover as crianças de um instrumento eficiente de expressão, intercomunicação social, aquisição de conhecimentos, ocupação proveitosa das horas de lazer e utilização da leitura nos seus aspectos recreativos, informativos e formativos. Silva (2012) destaca que, embora o prazer de ler e ouvir histórias tenha ganhado evidência no cenário nacional brasileiro na década de 1980, com a propagação das ideias sobre ensino de língua portuguesa propostas pelo linguista João Wanderley Geraldi, a importância da formação do hábito de leitura já vinha sendo desenvolvida desde os primórdios do movimento escolanovista.

Na capa do V livro de leitura, somente um menino branco é representado, este aparece sentado estudando tendo ao fundo a bandeira do Brasil, imagem esta que em muito remete às tradicionais lembranças escolares que ainda hoje são retratadas nas escolas. A bandeira do país também aparece ao fundo da capa do IV livro de leitura, mas desta vez a imagem que ganha destaque é a de três meninos que representam as três etnias que originaram o povo brasileiro (o negro, o índio e o branco). A imagem indica que as três crianças, mesmo com origens diferentes, teriam o fato de serem brasileiros como algo constituidor de suas identidades. Acreditamos que a preocupação em representar as três etnias se deva à ideia de valorizar a formação do povo brasileiro e à constituição de uma identidade nacional, uma vez que as questões étnicas não eram uma preocupação da época. Trindade (2004) chama a atenção para o uso de livros didáticos, desde o início do Brasil república, como instrumento utilizado para a subjetivação das pessoas favorecendo a formação de uma identidade nacional. Na região da CAND, a propagação deste discurso se fazia necessária dentro dos objetivos de ocupação e desenvolvimento do Governo Federal uma vez que a hegemonia identitária ainda não estava consolidada, pois a região estava se constituindo demograficamente. Mais uma vez Silva e Bertoletti (2017) identificam na legislação estadual uma forma de consolidação deste discurso. A Lei $n^{\circ}$ 452, de 24 de novembro de 1951, Lei Orgânica do Ensino Primário do estado de Mato Grosso, que como afirmado anteriormente foi inspirada no Decreto-lei $n^{\circ} 8.529$, de 2 de janeiro de 1946 - Lei Orgânica do Ensino Primário -, traz como sendo a finalidade do Ensino Primário proporcionar a iniciação cultural, o desenvolvimento de virtudes morais e cívicas, o desenvolvimento da personalidade e levar o nível dos conhecimentos necessários para o convívio familiar, à manutenção da saúde e à iniciação no trabalho. Estes princípios tornam-se ainda mais evidentes ao analisarmos os textos que compõem os materiais investigados.

Cada livro traz textos voltados para uma temática, além dos eixos comuns a todas elas como veremos a seguir. A cartilha apresenta textos referentes à vida de Lalá. O I livro de leitura traz textos relacionados a Lalá, sua escola, sua família e ao circo, local onde sua família trabalhava. No II livro de leitura os textos giram em torno do tema família, porém não mais à de Lalá, mas sim a famílias 
identificadas por pai, mãe e filhos, sendo que somente estes últimos eram denominados com nomes próprios. As histórias trazem temáticas do universo infantil como brincadeiras, vida cotidiana, aniversário. O tema família também acompanha os III, IV e V livros de leitura, mas nesses exemplares temas pedagógicos, morais, religiosos e pátrios ganham intensidade deixando de lado as temáticas mais infantis.

São recorrentes em todos os exemplares da coleção temas relacionados à pátria (símbolos nacionais, belezas naturais, fauna e flora, heróis e personalidades, riquezas, curiosidades regionais do povo brasileiro, lendas, progresso tecnológico, entre outros), aos conteúdos pedagógicos (meios de comunicação e de transporte, sinais de trânsito, cuidado com plantas e animais, higiene física, da cidade e mental, a água, energia, datas comemorativas), à moral (que trabalham as ideias de bondade, honestidade, perseverança, verdade...) e à religiosidade.

No que diz respeito à família, esta é apresentada como um núcleo harmonioso. O patriarcalismo é a regra, somente famílias em que o pai morreu são comandadas por mulheres, sendo essas dignas de piedade. Os filhos são obedientes, educados e estudiosos. A mãe é bondosa e dedicada. $O$ trecho do texto intitulado $A$ família demonstra a forma como os discursos são produzidos:

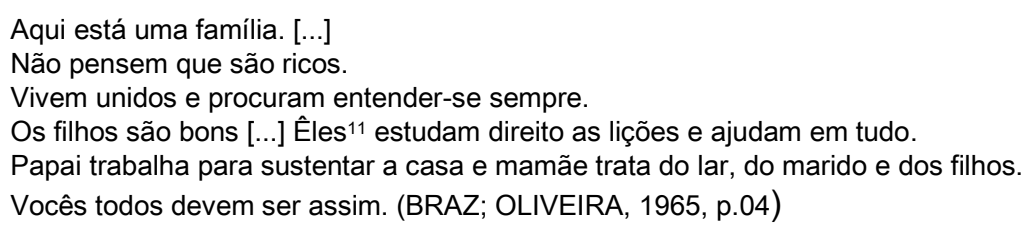

Desde o início da República como regime de governo no Brasil, a família era tida como uma das bases para a produção de uma nova identidade. A influência positivista e desenvolvimentista da época tentava afastar da subjetividade do brasileiro a ideia de um povo matuto, atrasado, promíscuo... As ideias de modernização e progresso estavam em alta e a organização de núcleos sólidos favoreceria a constituição desta nova identidade. É comum nos textos da cartilha a bondade e a pobreza serem retratadas como virtudes atreladas à honra. Segundo Trindade (2004), a família é apresentada nas cartilhas como um mundo à parte, em si e para si, desvinculada da realidade social e econômica. Nelas, as organizações funcionam, sendo modelo para outros grupos sociais.

A religiosidade é outro tema presente em todos os livros da coleção. Embora a primeira Constituição republicana, promulgada em 1891, já tivesse proclamado o Estado Laico, os temas envolvendo santos e santas católicos e datas referentes a eles são recorrentes. Orar e agradecer a Deus, a Jesus e a sua mãe, Maria, são atividades incentivadas pelos textos da coleção. O II livro de leitura da coleção traz o texto Vamos rezar que serve como ilustração do que estamos afirmando.

「...1 Esta família é feliz borque tem Deus no coração.

E vocês rezam também?

11 Os textos foram transcritos de acordo com as normas ortográficas da época. 
Devem rezar não só aos domingos; devem rezar todos os dias, mesmo que seja esta simples oracão:

Meı Deus muito obriaado!

Muito obrigado, meu Deus! (BRAZ; OLIVEIRA, 1965, p.26)

Aparentemente, a religiosidade, pela grande influência que exercia sobre o povo, é percebida como outra base sólida e produtora de discursos. Nela, os princípios da virtude e da moral eram trabalhados. Tornar-se ou ser bom e virtuoso é um discurso presente nos textos religiosos da cartilha e dos livros analisados. As graças divinas são alcançadas se a honra, a bondade e o altruísmo fizerem parte da identidade dos indivíduos, enfim, a educação moral era apresentada nos livros e na cartilha por meio de histórias religiosas e outros textos de cunho moralista como o que segue:

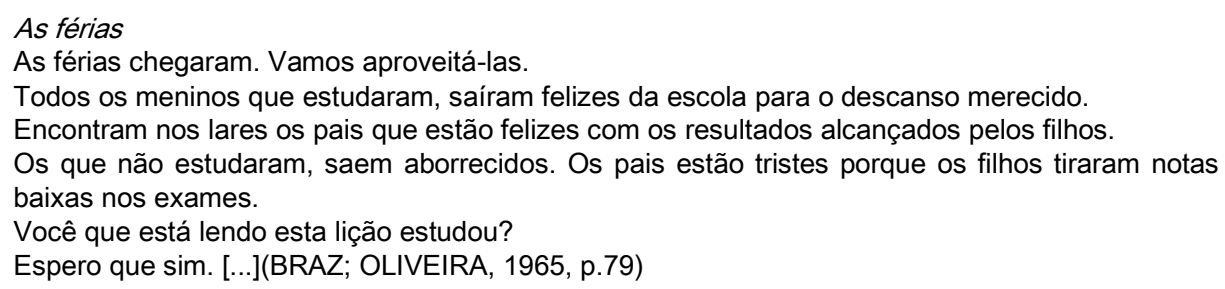

A escola é outra instituição muito presente nos livros analisados. Os textos demonstram a importância desse espaço para a formação de um homem de valor. Nela, as crianças respeitam e sentem orgulho de seus professores, são estudiosas, asseadas, caprichosas e inteligentes. A preguiça é castigada com a decepção dos que as querem bem ou com a reprovação e a nota baixa nos exames. O estudo é visto como uma preparação para o trabalho futuro. Um exemplo do que tratamos pode ser percebido no texto que segue:

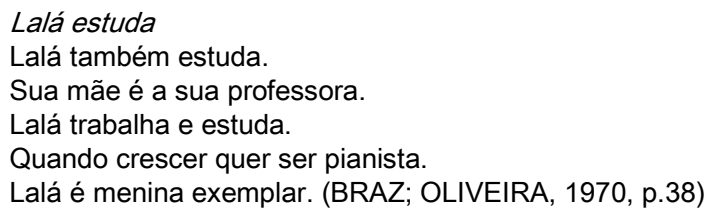

Mais uma vez é possível perceber como os textos subjetivavam os alunos influenciando sua formação, visando a formar o indivíduo para torná-lo um bom filho, um bom aluno e, no futuro, um bom trabalhador e um bom cidadão, ou seja, considerando sempre um "vir a ser".

O discurso nacionalista reflete-se no amor e orgulho que as crianças deveriam ter pela pátria. Os textos apresentam os símbolos nacionais, os quais deveriam ser venerados, pois representam, segundo os livros da coleção, o orgulho de ser brasileiro, e os heróis e as figuras importantes, que serviriam de exemplo para as futuras gerações. Um texto nos chama atenção por tratar exatamente do projeto desenvolvimentista e de ocupação das terras que originaram a CAND. Segue um fragmento: 


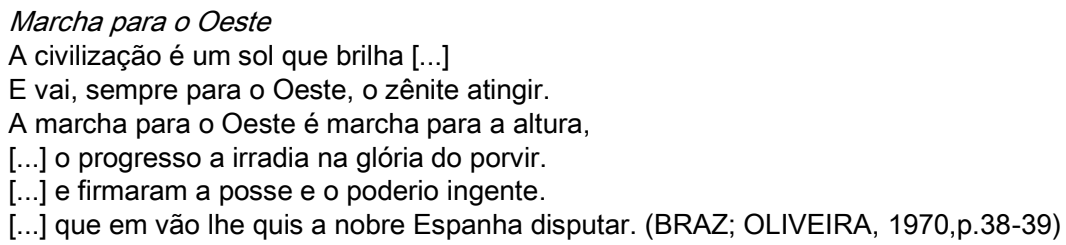

Como fica claro neste fragmento, a Marcha para o Oeste tinha como objetivo trazer progresso e civilidade ao povo da região, além de constituir uma nova identidade a este povo formado até então por uma maioria de índios e "brasiguaios". A ocupação das terras pelo "homem brasileiro civilizado" que amasse a pátria e a defendesse dos estrangeiros, no caso, paraguaios, de quem as terras foram conquistadas na Guerra do Paraguai e que ainda tinham forte influência no desenvolvimento econômico da região, era um dos objetivos do governo para o povo da região, por isso a necessidade de propagar discursos que subjetivassem o povo constituindo uma nova identidade, a de ser brasileiro.

Trindade (2004) lembra-nos que desde o final do século XIX a leitura era um dispositivo importante para a educação cívica e moral, que poderia ser adquirida por meio dos livros de leitura e cartilhas da época. A ideologia que informa os aspectos ligados à cidadania nos textos das cartilhas geralmente se refere à família, à escola e à pátria.

O progresso do Brasil é narrado com orgulho, trata-se das conquistas tecnológicas, das novas máquinas, das ferrovias, da energia elétrica, da urbanização. $O$ discurso higienista também é descrito como sendo uma conquista deste "povo civilizado" que está constituindo o "novo" Brasil. Propagam-se os cuidados com a higiene física e mental do indivíduo, do espaço doméstico e dos outros espaços em que se vive, até atingir o espaço urbano como um todo.

Segundo Freire (1989), foi a partir da segunda metade do século XIX que começaram, com mais frequência, a surgir, no país, livros nacionais de leitura destinados especificamente às séries iniciais da escolarização. Acompanhando tal movimento, as cartilhas escolares passaram a ser utilizadas com mais frequência nas escolas primárias. Com o início da República (1889), estruturaramse com mais acuidade as discussões sobre livros didáticos e métodos de alfabetização no Brasil, uma vez que então se pretendia constituir uma nova identidade nacional (FREIRE, 1989). Para Trindade (2004), "No caso dos livros de leitura, que incluiriam as cartilhas ou primeiros livros, a valorização da língua materna é destacada por ser importante à nossa identidade nacional, juntamente com a educação moral, cívica e intelectual".

\section{CONSIDERAÇÕES FINAIS}

Com este artigo pretendemos mostrar como as lutas de poder-saber são travadas e a forma como, por meio dos discursos, se produzem subjetividades que acabam por constituir identidades. 
No caso analisado, demonstramos como os livros escolares que chegaram até a região da CAND foram utilizados como dispositivos de governo para subjetivar a infância produzindo nela os valores com que se queria configurar a cidadania do futuro. Para isso, os conteúdos culturais, os aspectos materiais da coleção e a linguagem de textos expressavam, quase sempre, o pensamento e o discurso dos grupos que haviam vencido as "lutas" pelo poder-saber e que controlavam a instrução escolar, neste caso, estamos tratando do discurso republicano que visava a constituir uma identidade nacional ao povo brasileiro e ao progresso e desenvolvimento do país. Sendo assim, aos livros didáticos não eram atribuídas apenas utilidades pedagógicas estreitas, uma vez que eram utilizados pelo governo para constituir identidades, valores e culturas.

Os textos e as imagens presentes na coleção Vamos Sorrir contribuíram para a consolidação de uma política de desenvolvimento da região da CAND, para a constituição de um sentimento de nacionalidade e para a apropriação definitiva do território nacional por meio do "desenvolvimento" de virtudes morais e cívicas. Os discursos em torno da família, da igreja, da escola e da pátria acabaram por constituir a identidade daquele povo.

Além do discurso republicano desenvolvimentista localizamos nos livros da série de leitura analisados o discurso higienista e da Escola Nova que marcaram as narrativas da época. Tudo isso nos faz ponderar que, como destaca Trindade (2004), a possibilidade de interpretar as teorias como discursos não nos dá um olhar privilegiado sobre elas; contudo, nos permite compreendê-las não mais (ou somente) como produtos de autorias, mas como produção cultural e coletiva, contextual e histórica, nas quais em seus deslocamentos, sofrem os efeitos de mudanças das práticas que as produzem. Diante disso, interpretar as teorias como discursos permite identificá-las como artefatos construtivos de práticas, comunidades e identidades sociais ou de sujeitos.

Por fim, podemos inferir que os livros didáticos foram elementos-chave para a construção de uma identidade nacional ao povo da região, colonizada por um grande número de estrangeiros e que pertencia a uma região de fronteira. Acompanhando certo projeto de "brasilidade" se tentou instituir no povo a crença na religião e nos valores morais, de inspiração católica, já que os imigrantes tinham trazido consigo uma diversidade de crenças, valores e formas de pensar, sendo tal instituição importante para a formação de um cidadão que pudesse levar o país à unidade, ao progresso e ao desenvolvimento tão almejado na época.

\section{REFERÊNCIAS}

1. AMANCIO, Lázara Nanci de Barros; CARDOSO, Canciolina Janzkovski. Parte III - Mato Grosso. In: FRADE, Isabel Cristina Alves da Silva; MACIEL, Francisca Izabel Pereira (org.). História da alfabetização: produção, difusão e circulação de livros (MG/RS/MT - Séc. XIX e XX). Belo Horizonte: UFMG/Fae, 2006, p. 187-278. 
2. ARFUCH, Leonor . Identidades, sujetos y subjetividades. Buenos Aires: Trama Editorial, 2002.

3. BARKER, Chris; GALASINSKI, Dariusz. Cultural Studies and Discourse Analysis. In: A dialogue on language and identity. London: Sage, 2001. P.01-27.

4. BERTOLETTI, Estela Natalina Mantovani; SILVA, Márcia Cabral. Cultura escrita na escola primária: a circulação de livros didáticos para ensino de leitura (1928-1961). Revista Brasileira de História da Educação, Maringá, v.16, n.1, p. 373-403, jan/abr. 2016.

5. COSTA, Marisa V.; SILVEIRA, Rosa Hessel; SOMMER, Luis Henrique. Estudos Culturais, educação e pedagogia. Revista Brasileira de Educação, Rio de Janeiro, n. 23, p. 36-61, maio/ago. 2003. Estudos culturais - para além das fronteiras disciplinares. In: (org.). Estudos Culturais em educação. Porto Alegre: Ed. Universidade/UFRGS, 2000. p. 13-36.

7. DARNTON, Robert. O beijo de Lamourette. São Paulo:Companhia das Letras, 1990.

8. EVANGELISTA, Aracy Alves Martins; ROCHA, Gladys A. Sá. Como são vistos os leitores-alunos nos livros para alfabetização? In: ASSOCIAÇÃO NACIONAL DE PÓS-GRADUAÇÃO E PESQUISA EM EDUCAÇÃO, 21, 1998, Caxambu. Anais. Caxambu: ANPEd, 1-4, set. 1998. p.1-15. FREIRE, Ana Maria Araújo. Alfabetização no Brasil. São Paulo: Cortez: Brasília, DF:INEP, 1989. FOUCAULT, Michel. A ordem do discurso. São Paulo: Loyola, 1996.

11. GILL, Rosalind. Análise do Discurso. In: BAUER, Martin W.; GASKELL George. Pesquisa qualitativa com texto, imagem e som: um manual prático. Petrópolis: Vozes, 2004. p. 244-270. colonização do Estado de Mato Grosso do Sul: destaque especial ao município de Dourados. Dourados: L.A. Gressler, 1988. 
14.

IRALA, Clóvis. ; NASCIMENTO, Aline Cavalcante ; FURTADO, Alessandra Cristina. Fontes para o estudo da escola primária rural no sul do antigo Mato Grosso (1940-1970). In: XII ENCONTRO DE PESQUISA EM EDUCAÇÃO DO CENTRO-OESTE,12., 2014, Goiânia. Anais Pós-Graduação e Pesquisa em Educação: contradições e desafios para a transformação social. Goiânia: ANPED, 1922 out. 2014. p. 1-15.

LARROSA, Jorge. Narrativa, identidad y desidentificación. In: La experiencia de La lectura. Barcelona: Laertes, 1996.

LUKE, Allan. Análise do discurso numa perspectiva crítica. In: HYPÓLITO, Álvaro Moreira; GANDIN, Luís Armando. Educação em tempos de incertezas. Belo Horizonte: Autêntica, 2000. p. 93-110.

MATO GROSSO. Diretrizes para a Educação do Mato-Grosso. Cuiabá, MT, março de 1965.

MATTELART, Armand. Introdução aos Estudos Culturais. São Paulo: Parábola, 2004.

MOREIRA, Kênia Hilda. Um balanço das pesquisas em História da Educação no Brasil com o livro didático: questões sobre fonte, temas e métodos. In: XI CONGRESSO IBERO-AMERICANO SOBRE A HISTÓRIA DA EDUCAÇÃO LATINO-AMERICANA, 11, 2014, Toluca-México. Anais. , Toluca: CIHELA, 6-9, mai. 2014. p.01-15.

PERES, Eliane. O ensino de linguagem na escola pública primária gaúcha no período da Renovação Pedagógica. In: PERES, Eliane; TAMBARA, Elomar (org.). Livros escolares e ensino da leitura e da escrita no Brasil (séculos XIX - XX). Pelotas: Seiva Publicações \& FAPERGS, 2003. p.75-116.

21. PONCIANO, Nilton Paulo. Fronteira, religião, cidade: o papel da Igreja Católica no processo de organização sócio-espacial de Fátima do Sul/MS (1943 - 1965). 2006. 221f. Tese (Doutorado em História) - FCL/UNESP, Assis. 
SILVA, Tomaz Tadeu da. Documentos de identidade: uma introdução às teorias do currículo. Belo Horizonte: Autêntica, 1999.

SILVA, Thaise da. A circulação de livros voltados para a alfabetização no sul do Mato Grosso.

Revista de Estudos de Cultura, São Cristóvão: Universidade Federal de Sergipe, n. 9, p. 89-96, set/dez. 2017.

fundamental de nove anos do Programa Nacional do Livro Didático (PNLD 2010). 2012.

283f.Tese (Doutorado em Educação) - UFRGS, Porto Alegre.

25 . ; BERTOLETTI, Estela Natalina Mantovani. Políticas de circulação de livros didáticos de alfabetização no sul de Mato Grosso e seus métodos (1927-1961). Revista Poiésis,

Tubarão: Revista do Programa de Pós-Graduação em Educação (Unisul), v. 11, n.20, p. 268286, jun/dez, 2017.

26. "Novas rotas" de circulação das cartilhas no extremo sul de Mato Grosso. n.d. (Artigo submetido a avaliação do periódico Cadernos de História da Educação - aguardando resultado)

TRINDADE, Iole Maria Faviero. A invenção de uma nova ordem para as cartilhas: ser maternal, nacional e mestra. Queres ler? Bragança Paulista: Editora Universitária São Francisco, 2004.

28. VEIGA-NETO, Alfredo. Cultura, culturas e educação. Revista Brasileira de Educação. Rio de Janeiro. n.23, p. 05-15. maio/ago 2003.

29. Michel Foucault e educação: há algo de novo sob o sol? In: (Org.). Crítica pósestrturalista e educação. Porto Alegre: Sulina, 1995, p. 09-56.

\section{OBRAS ANALISADAS}

1. BRAZ, M. Vamos Sorrir: cartilha.10ª edição. São Paulo, FTD, 1973. 

. Vamos Sorrir: Livro do Professor. São Paulo, FTD, s.d. ; Cândido de Oliveira. Vamos Sorrir:I livro de leitura.8ª edição. São Paulo, FTD, 1973.

4. Vamos Sorrir: Il livro de leitura. São Paulo, FTD, 1965.

5. Vamos Sorrir: III livro de leitura. São Paulo, FTD, 1973.

6. Vamos Sorrir: IV livro de leitura. São Paulo, FTD, 1970.

7. . Vamos Sorrir: V livro de leitura. São Paulo, FTD, 1968.

\section{Thaise da Silva:}

Professora permanente do Programa de Pós-graduação em Educação da Universidade Federal da Grande Dourados - Mato Grosso do Sul (UFGD) e professora adjunta da área de Currículo e Alfabetização (UFGD). Líder do Grupo de Estudos e Pesquisas em Educação Infantil e Infância (GEINFAN) do diretório do CNPq. Tem graduação em Pedagogia pela Universidade Federal do Rio Grande do Sul (UFRGS - 2000), especialização em Alfabetização pela Faculdade Porto-Alegrense (FAPA - 2004), mestrado em Educação pela UFRGS (2008) e doutorado em Educação pelo Programa de Pós-Graduação da mesma instituição (2012).

\section{Estela Natalina Mantovani Bertoletti:}

Licenciada em Letras pela Universidade Federal de Mato Grosso do Sul (1990); Mestre em Educação pela Universidade Estadual Paulista Júlio de Mesquita Filho (1997); Doutora em Educação pela Universidade Estadual Paulista Júlio de Mesquita Filho (2006); pós-doutorado em Educação Escolar pela Universidade Estadual Paulista Júlio de Mesquita Filho (2011); pós-doutorado em Educação na Universidade do Estado do Rio de Janeiro (2014). É professora da Universidade Estadual de Mato Grosso do Sul, atuando no curso de Pedagogia, especialização em Educação e mestrado em Educação. 


\section{Como citar este documento:}

SILVA, Thaise da; BERTOLETTI, Estela Natalina Mantovani. A PRODUÇÃO DE IDENTIDADES SULMATO-GROSSENSES NAS PÁGINAS DAS CARTILHAS. Reflexão e Ação, Santa Cruz do Sul, v. 26, n. 2, $2018 . \quad$ ago. ISSN 1982-9949. Disponível em: $<$ https://online.unisc.br/seer/index.php/reflex/article/view/11710 $>$. Acesso em: doi:http://dx.doi.org/10.17058/rea.v26i2.11710. 